\title{
WIND ENERGY POTENTIAL IN KUCHING AREAS OF SARAWAK FOR SMALL-SCALE POWER APPLICATION
}

\author{
S. M. Lawan ${ }^{1,2, a^{*}, \text { W. A. W. Z. Abidin }}{ }^{1, b}$, W. Y. Chai ${ }^{3, \mathrm{c}}$ A. Baharun ${ }^{4, d}$, \\ and T. Masri ${ }^{1, \mathrm{e}}$ \\ ${ }^{1}$ Department of Electrical and Electronics Engineering, Faculty of Engineering, Universiti Malaysia \\ Sarawak (UNIMAS) \\ ${ }^{2}$ Department of Electrical Engineering, Kano University of Science and Technology, Wudil, Nigeria \\ ${ }^{3}$ Department of Computing and Software Engineering, Faculty of Computer Science and \\ Information Technology, Universiti Malaysia Sarawak (UNIMAS) \\ ${ }^{4}$ Department of Civil Engineering Faculty of Engineering, Universiti, Malaysia Sarawak (UNIMAS) \\ *a13010004@siswa.unimas.my, bwaazlan@feng.unimas.my, cycwan@fit.unimas.my, \\ dbazhaili@feng.unimas.my, ${ }^{\mathrm{d}} \mathrm{m}$ thelaha@feng.unimas.my
}

Keywords: Sarawak, Kuching, Small-scale, Wind speed, Wind energy.

Abstract. Energy is a catalyst for national development; most of the countries depend on hydrocarbon fuels for power generation. The traditional sources of energy are exorbitant and finite. In addition, they emit excessive carbon dioxide and other gases into the lower layer of the atmosphere, which influence the increase occurrence of global warming in the world. Recently, renewable energy's are gaining more attraction and attention in many parts of the globe, due to nonpolluting characteristics. Among the renewable, wind power has emerged as safest and cleanest resource that will satisfy the need of energy in a cost effective way. Wind energy system can suit the energy need for grid and stand-alone mode. This paper investigates the potential of wind energy in Kuching for small-scale power application. The study employed three years wind speed data spanning from 2010-2012 observed at the Kuching meteorological station. Details of the analysis carried out and potential of using wind energy systems are presented. Additionally, the output performances of two wind turbines are examined based on the computed Weibull distribution.

\section{Introduction}

Wind is a reliable, clean source of energy and the main opponent of fossil fuels because of the emission-free characteristics. In recent times, considerable attention has been devoted to utilizing the abundant resources. The merits of using this type of zero-emission energy when compared to other renewable energies, wind power can operate during the day and night time, and does not require numerous accessories, unlike solar power. Rapid development, urbanization, and population growth make renewable energy grew to be well known and recognized in the entire world. The substantial utilization of hydrocarbon energy sources has enhanced the generation of greenhouse gasses and other polluting materials; moreover, the resources are finite since they reduce after some spans [1-3].

Wind can produce clean resources of electric power in the environment: residential and industrial areas. In addition, wind is a guaranteeing useful resource that can serve zero-emission energy to non-urban and remote residents in non-grid mode conveniently. Though, vertical axis wind turbines (VAWT) have been demonstrated to perform excellently in the quiet windy areas [3-6]. However, horizontal-axis wind turbines (HAWT) are frequent and widespread installed wind turbines. Nowadays, HAWT aerodynamics is also admired for low wind speed areas. One study [5] verified the feasibility of installing two small wind speed driving generators, for the lagoon of Venice in Italy, using 2- years anemometry measurement performed within study area.

Wind flow is site specific and deviates with time and locations. To take advantage of the energy content in the wind by means of small wind drive systems successfully, the average annual wind speed and Weibull distribution are precondition requirements that are essential to the setting up 